\title{
Syndecans in Inflammation at a Glance
}

\section{Sandeep Gopal*}

Development and Stem Cells Program, Department of Anatomy and Developmental Biology, Monash Biomedicine Discovery Institute, Monash University, Melbourne, VIC, Australia

Syndecans are transmembrane proteoglycans with heparan and chondroitin sulfate chains attached to their extracellular domain. Like many proteoglycans, they interact with a large number of ligands, such as growth factors, adhesion receptors, soluble small molecules, proteinases, and other extracellular matrix proteins to initiate downstream signaling pathways. Syndecans play a major role in inflammation, mainly by regulating leukocyte extravasation and cytokine function. At the same time, syndecans can undergo cytokine mediated changes in their expression levels during inflammation. The function of syndecans during inflammation appears to depend on the stage of inflammation, sulfation of heparan/chondroitin sulfate chains, the rate of ectodomain shedding and the solubility of the ectodomains. From the current literature, it is clear that syndecans are not only involved in the initial recruitment of pro-inflammatory molecules but also in establishing a balanced progression of inflammation. This review will summarize how cell surface and soluble syndecans regulate multiple aspects of inflammation.

Keywords: syndecan, proteoglycan, extravasation, inflammation, shedding, cytokines, chemokine gradient

\section{INTRODUCTION}

Inflammation is the immediate response of the body to combat an infection or injury. It is a cascade of complex immunological events resulting from the disruption of tissue homeostasis, which acts to remove the source of infection or restore damaged tissue. When left unchecked, inflammation will result in further tissue damage and injury (1). Inflammation can either be acute or chronic. Acute inflammation (e.g., wounding) is a controlled short-term process that results in the healing of the damaged tissue or the removal of infection, whereas chronic inflammation (e.g., cancers) is a persistent response that leads to further tissue damage. Chronic inflammation often does not present visible cardinal signs of inflammation, such as redness (rubor), increased heat (calor), swelling (tumor), pain (dolor), or loss of function (functio laesa) (2). However, it can lead to more serious conditions, such as fibrosis and cancers $(3,4)$. Inflammation is associated with modifications to the local vasculature and elevated blood flow that permits the recruitment of leukocytes, plasma proteins, and soluble molecules to the site of inflammation (5). Key steps in inflammation involve recognition of the inducers, signal transduction, release of pro-inflammatory molecules, activation of the effectors of inflammation, and resolution of the inflammation (6). The inducers are recognized by a range of receptors, such as toll-like receptors and nucleotidebinding domain and leucine-rich-repeat-containing receptors, leading to the activation and nuclear translocation of the transcription factor NF-кB (7-9). This induces the expression of a number of pro-inflammatory cytokines, such as interleukin- $1 \beta$ (IL-1 $\beta$ ), IL-6, IL-8, IL-12, and Tumor Necrosis Factor- $\alpha($ TNF- $\alpha)$. While several molecules are involved in inflammation, cytokines play a central role as both pro-inflammatory and anti-inflammatory molecules (6). However, the classification 


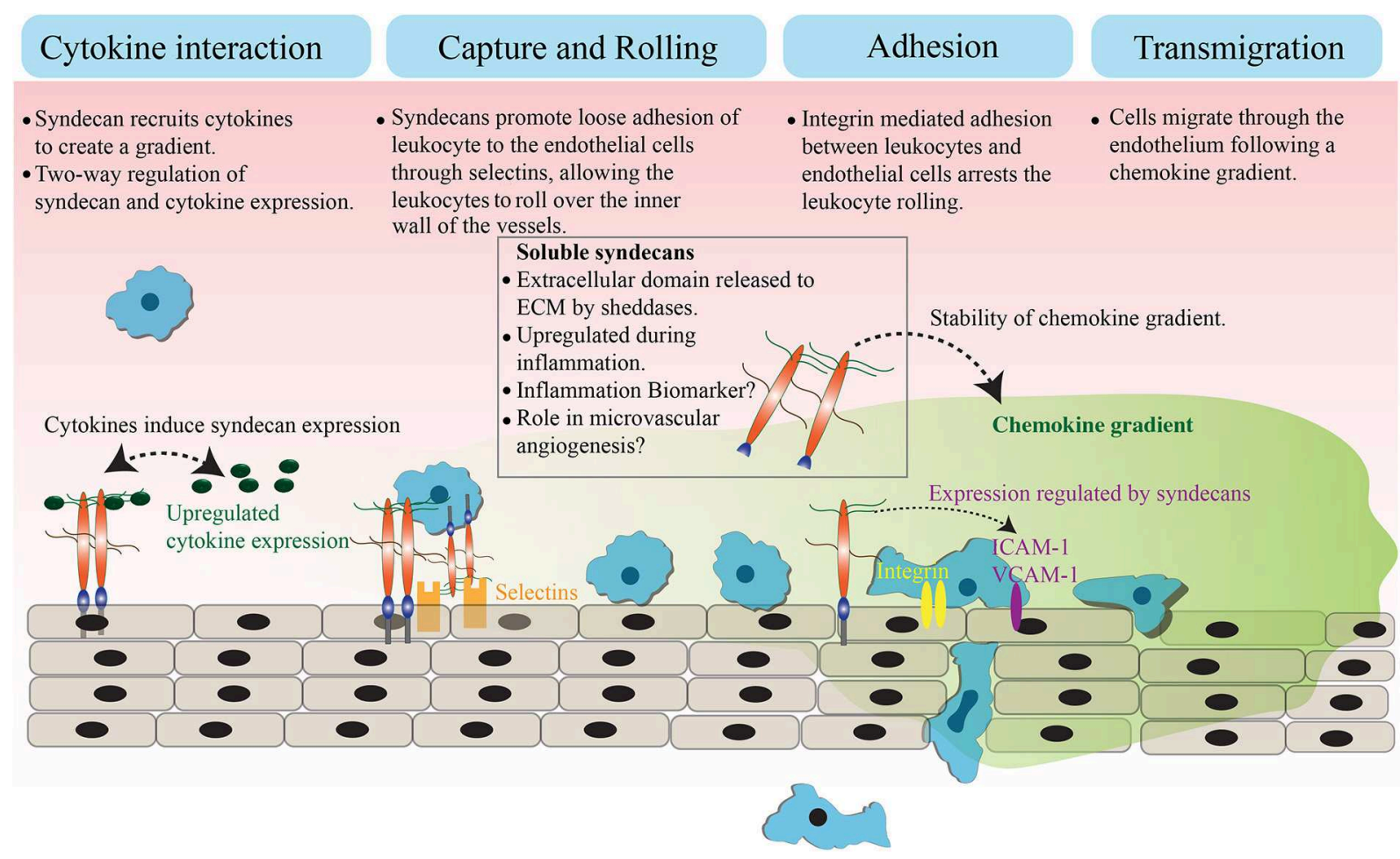

FIGURE 1 | Role of syndecans in extravasation. Syndecans bind to inflammatory cytokines and chemokines through GAG chains. This interaction appears to trigger a feedback signaling, which results in an elevated expression of both syndecan and cytokines. The GAG chain mediated binding of syndecan with chemokine and the subsequent shedding of syndecan-chemokine complex results in a stable chemokine gradient. Syndecans mediate a loose interaction between leukocytes and endothelial cells through selectins, which reduces the pace of leukocyte movement and they bigin to roll over the vessel surface. The adhesion between leukocytes and endothelial cells is strengthened by an integrin controlled signaling and other cell adhesion molecules, leading to the arrest of leukocyte rolling. Attached leukocytes begin transmigration directed by a stable chemokine gradient to the site of inflammation.

of pro-inflammatory and anti-inflammatory is not absolute, as some of the cytokines are known to play both roles (10). In the next stage, effector cells, such as neutrophils and monocytes are recruited to the site of inflammation leading to a process called degranulation (11). Neutrophils expedite the release of reactive oxygen species, reactive nitrogen species, and protein degrading enzymes. This creates a highly toxic environment for pathogens as well as the host tissue, leading to the destruction of both. In the final phase of inflammation, macrophages ensure minimal damage to the host tissue by restricting neutrophil migration while enhancing monocyte recruitment to the site of inflammation $(11,12)$.

\section{SYNDECANS IN INFLAMMATION}

Syndecans are transmembrane proteoglycans that can interact with a large number of ligands including growth factors, adhesion receptors, cytokines, chemokines, proteinases, and other extracellular matrix proteins (13). As a result of these ligand interactions, syndecans initiate a number of biological signaling events relevant to cell adhesion, angiogenesis, inflammation, and tissue repair (14-18). The mammalian genome encodes four syndecans; syndecan $-1,-2,-3$, and -4 . Syndecans not only maintain cell homeostasis under normal conditions but also regulate inflammatory responses during infection and trauma (Figure 1). Syndecans are one of the major sources of glycosaminoglycan (GAG) chains on the cell surface. They control a large number of cytokines though GAG chain mediated binding to stimulate inflammatory response (1921). While syndecan-1 is the most studied syndecan in the context of inflammation, other syndecans are also shown to have roles in inflammatory response in various models. Syndecan-1 and -4 knockout mouse models have provided a great deal of information about the role of syndecans in inflammation, where they appear to be involved in multiple aspects of inflammation from leukocyte recruitment through to the resolution of inflammation $(22,23)$. One common observation during inflammation is that the total expression of syndecans at protein level can be significantly upregulated $(21,24)$. For instance, the levels of syndecan-1 and syndecan4 are elevated during myocardial injury. Similarly, syndecan2 expression is upregulated in endothelial cells, fibroblasts and intestinal epithelial cells by inflammatory stimuli, such as $\mathrm{TNF} \alpha$ or hypoxia $(25,26)$. It has been previously reported that the level of syndecans in the serum of animals is directly related to the severity of the inflammation $(27,28)$. Other reports suggest that the loss of syndecans from cells, possibly by shedding, regulates inflammatory responses (28). This review will discuss the role 
of cell surface and soluble syndecans in cytokine regulation and leukocyte extravasation with a focus on syndecan $-1,-2$, and -4 , while syndecan-3 is discussed in detail in another review of this issue.

During leukocyte extravasation, the leukocytes move out of circulation and adhere in proximity to the sites of inflammation (6). Syndecans, along with glypicans are the major heparan sulfate proteoglycans (HSPG) that control this process (22, $29,30)$. HSPGs loosely bind to L- and/or P-selectins on the inner wall of vessels to slow down the flow of leukocytes (31), leading to leukocyte rolling on the surface of the endothelium. This suggests the involvement of HSPGs as pro-inflammatory molecules, specifically to support leukocyte rolling. However, knockout studies showed an elevated inflammatory response in the absence of syndecan- 1 or syndecan- 4 in mice, indicating that syndecans are inflammation antagonists instead $(22,28,32)$. These observations were explained when an increase in leukocyte adhesion and transendothelial migration with prolonged edema formation was identified in syndecan-1 knockout mice subjected to a myocardial infarction (33). Another report suggests that syndecan-1 is essential to limit inflammation and apoptosis during lung injury after an influenza infection (34). Similarly, syndecan-1 is required to maintain the motility of macrophages during chronic inflammation in atherosclerosis, where the absence of syndecan-1 resulted in persistent inflammation (35). In addition to that, syndecan-1 knockout mice exhibit increased expression of pro-inflammatory cytokines (TNF $\alpha$, IL-6, CCL5 , and CCL-3) and adhesion molecules (ICAM-1 or VCAM1) during oxazolone-induced delayed-type hypersensitivity and dextran sodium sulfate-induced colitis $(36,37)$. These data support the idea that syndecan-1 is anti-inflammatory. The negative regulation of strong leukocyte adhesion to endothelium by syndecan-1 is proposed to be the reason behind its antiinflammatory role. In general, strengthening of leukocyte adhesion to the endothelium is the penultimate step of leukocyte extravasation, which is mediated by integrins and adhesion molecules (e.g., ICAM-1, VCAM-1). It has been suggested that syndecan-1 may oppose integrins, likely by competition for ligands to control strong leukocyte adhesion. Therefore, the absence of syndecan-1 may have promoted integrin mediated leukocyte adhesion to the endothelium (38). Taken together, syndecan-1 appears to support the initial regulation of leukocyte movement whereas it negatively regulates the later leukocyte adhesion and migration. Similar observations were made with syndecan- 4 , where chemotaxis experiments revealed that syndecan- 4 mediates anti-thrombin induced inhibition of leukocyte migration in a heparan sulfate chain-dependent manner (39). These observations indicate that syndecans function to create a balanced inflammatory response by controlling distinct aspects of leukocyte extravasation. In some chronic inflammatory diseases, such as asthma, syndecan4 also control T-helper 2 (Th2) derived immune response. Asthma is characterized by airway inflammation, which is caused by an inappropriate Th2 cell response. The blocking of syndecan-4 in ovalbumin sensitized mice resulted in a reduced inflammation due to the defective migration of antigen presenting dendritic cells. This affects the Th2 derived immune response where dendritic cells failed to deliver signals to Th2 cells (40).

It is well-known that the balancing of pro-inflammatory and anti-inflammatory molecules dictates the final outcome of an inflammatory response. The increase in leukocyte recruitment to the inflammation site is usually supported by an increase in the expression of cytokines and adhesion molecules. It has been reported that HSPGs can promote or inhibit both pro-inflammatory and anti-inflammatory cytokines by direct binding through their GAG chains (41-43). Depending on the model under investigation, different syndecans have shown to bind either pro-inflammatory or anti-inflammatory cytokines. Syndecans facilitate a gradient of a group of small cytokines, known as chemokines, during leukocyte rolling. For example, the binding of chemokines (e.g., IL-8) to syndecan-1 through GAG chains allows the stabilization of the chemokines on the endothelial surface and creates a tethering effect for the chemokine. The later shedding of the chemokine-Syndecan1 complex leads to a stable chemokine gradient $(44,45)$. This chemokine gradient appears to be crucial for maintaining the directionality of leukocyte migration (46). Another report showed that syndecan-1 regulates pro-inflammatory cytokine IL-17 during Psoriasiform Dermatitis, where the absence of syndecan-1 resulted in increased skin inflammation (47). Both syndecan-1 and IL-17 are shown to be increased in nasal polyps, a chronic inflammation in the nasal cavity (48). Syndecan-2 expression is elevated in endothelial cells during inflammation, where they can directly bind with cytokines (e.g., CXCL-8) and induce the expression of other cytokines (e.g., IL-1 $\alpha, \mathrm{IL}^{-17 \mathrm{~A}^{+}}$) $(25,49)$. The silencing of syndecan-4 in HUVEC cells resulted in an elevation of pro-inflammatory factors (e.g., CXCL-8), which suggests that a loss of syndecan-4 may result in an aggravated inflammatory response. This appears to agree with syndecan- 4 knockout mice studies, where lipopolysaccharide (LPS) induced pulmonary inflammation resulted in increased early neutrophil migration and higher titers of chemokines in bronchoalveolar lavage fluid. In this case, the expression of chemokines was reduced when the bronchial epithelial cells were pre-treated with heparin or syndecan-4 before LPS treatment (50). While syndecans appears to control inflammatory cytokines, the inverse is also possible, with the expression of syndecans being regulated by cytokines. In some cases, the same cytokines even have opposite effects on the expression of different syndecans. For instance, IL- $1 \beta$ and IL-6 treatment downregulated syndecan1 expression in isolated rat hepatocytes while syndecan-2 expression is upregulated by the same (51). The same study also reported an increase in syndecan-1 expression in response to a TNF- $\alpha$ treatment. Similar observations were made in human periodontal fibroblasts and osteoblasts (52). Growing HUVEC endothelial cells in the presence of inflammatory mediators, such as IL-1 $\beta$ and LPS resulted in a rapid elevation of syndecan- 4 expression (53). On the other hand, TNF- $\alpha$ treatment of HT29 cells resulted in the downregulation of syndecan-1 expression (54). These findings clearly indicate a feedback mechanism to control the expression of syndecans during inflammation. 
Further investigations are required to provide clarity to the effect of this feedback regulation on inflammation.

As syndecans show both pro- and anti-inflammatory roles in knockout models, one might wonder the reason behind this. For instance, an arthritis model generated by injecting CXCL1 into mice knee showed a decreased disease severity in syndecan-3 null mice compared to wildtype, possibly through a reduced neutrophil accumulation and cartilage degradation in null mice (55). However, the administration of CXCL1 into the skin resulted in increased neutrophil recruitment compared to wildtype animals (55). One explanation for this opposite effect could be, that syndecan-3 is promoting proinflammatory cytokines in skin and anti-inflammatory cytokines in the cartilage. Another explanation is that the deletion of syndecan-3 resulted in distinct response from other syndecans in each system under evaluation. This study did not examine the expression changes of other syndecans after syndecan3 deletion. This becomes relevant when the deletion of one syndecan leads to opposite inflammatory responses to same stimulus in different tissues. It is possible that the removal of syndecan-3 may have influenced the expression of different members syndecan family in each system, eventually leading to a compensatory or opposite response. Earlier studies regarding the role of syndecans in inflammation did not take potential compensation between syndecans into account. There is no obvious developmental phenotype for mice lacking syndecan1 or syndecan-4, which may indicate compensation between syndecans. However, when these mice are injured, they exhibit profound phenotypes. This leads to the question on whether the phenotype observed is a result of the loss of one syndecan or due to the compensatory effect by an alternate syndecan. In addition, each syndecan may be interacting with distinct cytokines and the second syndecan may be signaling through different ligands instead of simply compensating for the deleted syndecan.

Another aspect of syndecan function in inflammation yet to be addressed is their role in matrix turnover and mechanotransduction. ECM remodeling is observed during chronic inflammation, which is usually mediated by matrix degrading enzymes (e.g., Matrix metalloproteinases) (56). Cytokines promote the expression of catabolic enzymes leading to matrix degradation and turnover $(57,58)$. Since syndecans are one of the key regulators of cytokine function during inflammation, it is safe to assume that syndecans contribute to matrix turnover. ECM remodeling and increased deposition of ECM components are common during the development of fibrosis, a prominent outcome of chronic inflammation (59). Cardiac disease models showed that syndecan-1 mediates fibrosis resulting from an enhanced deposition of collagen $(60,61)$. Similar observations were made in the lung where syndecan-4 plays an important role in limiting lung fibrosis during inflammation $(62,63)$. ECM remodeling contributes significantly to the mechanical properties of the matrix. The role of mechanosignaling in leukocyte extravasation has been reported previously (64). While the role of syndecans as mechanosensors is not fully elucidated, they can play a significant role in mechanotransduction. Syndecan mediation of cell-matrix and cell-cell adhesion, and cytoskeleton organization has been extensively studied $(13,14,65-67)$. Therefore, it is safe to assume that syndecans may control mechanical forces generated by the adhesion associated molecules during inflammation. A previous report supports this notion, where the syndecan-1 knockout endothelial cells failed to form a phospho-paxillin gradient in response to the shear stress generated by atheroprotective flow. Paxillin is a structural protein in the focal adhesions and the defective phosphorylation of paxillin resulted in a proinflammatory phenotype (28). In addition, syndecan- 1 and-4 have shown to control the function of stretch-activated calcium channels in epithelial cells and fibroblasts, respectively. This could well be relevant for inflammation, where calcium is not only a known influencer, but also important in conditions, such as wound contraction and shear (68).

\section{SOLUBLE SYNDECANS IN INFLAMMATION}

Syndecans exist either as transmembrane form or as soluble extracellular domains (69). Proteolytic cleavage of syndecan core proteins at the juxtamembrane site is associated with inflammation, mainly as a result of the actions by enzymes called sheddases (e.g., MMPs, ADAMTS) (70). The cleavage of the core protein results in the delivery of extracellular domain to the matrix and then to the circulation. Several cytokines (e.g., IL-8, IL-17, TNF $\alpha$ ) can induce core protein cleavage by sheddases, likely by directly interacting with GAG chains (45). The cleaved core proteins, carrying glycosaminoglycan chains, are released to the extracellular matrix where they can bind to more extracellular matrix ligands. The shedding can have multiple effects on cell signaling. One, they rapidly downregulate signal transduction at the cell surface. Two, they can quench ligands and make them unavailable to the remaining syndecans on the cell surface. Three, they can initiate more signaling pathways as circulating soluble effectors, independent of cell surface signaling. The increase in the levels of soluble syndecans1 and syndecan-4 in the dermal wound fluid and high levels of syndecan-3 in the serum during rheumatoid arthritis have been observed $(41,71)$. Early studies showed that MMP-7 mediated syndecan-1 shedding to alveolar epithelium resulted in a stable CXCL1 chemokine gradient to promote neutrophil migration $(44,72,73)$. While this may depict syndecan-1 shedding as proinflammatory, it however allows a tight control of inflammation. The gradient formation restricts neutrophil migration at the site of epithelial injury, thus preventing further tissue damage (73). The CXCL1 secretion levels are reduced in syndecan-1 or MMP7 knockout animals, resulting in reduced neutrophil migration (72). In addition to CXCL1, shed syndecan is known to bind with chemokines, such as CCL7, CCL11, and CCL17, minimizing the Th2 cell recruitment to the lungs (74). More recent studies showed that syndecan-1 shedding is essential for the resolution of inflammation, likely by removing the sequestered CXC chemokines (75). It is also known that soluble syndecan-1 can reduce the expression of pro-inflammatory cytokines. For example, the administration of exosomes containing syndecan1 can be used to mitigate the expression of pro-inflammatory 
cytokines (e.g., IL-1 $\beta$, IL-6, TNF $\alpha$ ) and alleviate LPS induced acute lung edema and inflammation (76). While these results show that syndecan-1 shedding is required to alleviate or control inflammatory response, the opposite observations were also made. For instance, intestinal epithelial cells expressing shedding resistant syndecan-1 appears to be less prone to inflammatory damage. These experiments showed reduced neutrophil migration and $\mathrm{TNF} \alpha$ expression (72). A possibility worth considering is that the transient expression of shedding resistant syndecan may have resulted in very high levels of cell bound syndecan-1, leading to the activation of other signaling pathways. Similarly, hemorrhagic shock increases systemic shedding and a decrease in the pulmonary presence of syndecan-1, leading to increased inflammation (77). In light of the observations that soluble syndecan-1 is elevated under inflammatory conditions, it has been proposed that syndecan1 serum levels can be used as a biomarker for inflammation $(78,79)$. The increase in soluble syndecan-1 may occur in the later stages of inflammation. Therefore, the effectiveness of using soluble syndecan- 1 as a marker in early inflammation will need further study and more effective detection tools. On the other hand, the presence of soluble syndecan-1 may be used as a marker for the severity of diseases, such as neuromyelitis optica or inflammatory breast cancers $(27,80)$. A final aspect of inflammation that may have been associated with syndecan shedding is angiogenesis. Inflammation promotes angiogenesis, which further enhances chronic inflammation. In other words, inflammation and angiogenesis are mutually dependent (81, 82). Previous reports showed that syndecan-1 knockout mice have increased angiogenesis due to an increase in leukocyte adhesion (83). Similarly, soluble syndecan-1 ectodomain alters angiogenesis in syndecan-1 overexpressing mice. However, this may be due to the excess proteolytic activity resulted from the modulation of proteolytic enzymes by heparan sulfate chains on the shed syndecan-1 ectodomain (84). Previous reports shows that syndecan-2 signaling is essential for angiogenesis during development, while the shed syndecan-2 is known to inhibit angiogenesis $(17,85)$. Syndecan-4 ectodomain shedding is associated with both acute and chronic inflammation as well as angiogenesis. One report showed that pro-inflammatory molecule LPS induces the shedding of syndecan- 4 from the heart, possibly as a result of ADAMTS1, ADAMTS4, or MMP9 (61). The syndecan- 4 shedding during chronic inflammation caused by diabetes mellitus resulted in an impaired macrovascular angiogenesis (86). The same report showed that treating HUVEC cells with advanced glycation end products (AGEs) leads to syndecan-4 shedding. AGEs are the harmful compounds formed by sugar and protein or fat in the blood that are typically high during diabetes mellitus. These compounds are known to enhance the expression and function of pro-inflammatory cytokine $\mathrm{TNF} \alpha$, which can also promote syndecan shedding. The TNF $\alpha$ mediated shedding of syndecan -4 could well be the reason

\section{REFERENCES}

1. Medzhitov R. Origin and physiological roles of inflammation. Nature. (2008) 454:428-35. doi: 10.1038/nature07201 for the defective angiogenesis during inflammation caused by diabetes mellitus (86).

\section{PERSPECTIVES AND CONCLUSIONS}

The current findings conclude that, irrespective of the type, syndecans are elevated during inflammation. Independent studies have indicated that syndecans can act as both proinflammatory and anti-inflammatory molecules, with cell surface and soluble syndecans having distinct roles. The elevation in syndecan expression is required for initial leukocyte rolling and recruitment of chemokines. However, this needs to be limited as the signaling progresses. At this point, the expression of syndecans on the cell surface may have to be controlled, which could be achieved by shedding of syndecans. The shedding of syndecans can not only reduce the signaling from cell surface, but also create a stable chemokine gradient that directs the migration of leukocytes only to the vicinity of inflammation. These limiting steps may be crucial later on, in helping the clearance of inflammation. Even though the role of syndecans in inflammation is well-studied, there are several aspects that need further investigation. Previous reports have shown that pathogens exploit GAG chains on syndecans to infect the host $(87,88)$. However, there is no data supporting the idea that syndecans can recognize the inflammation inducers. This is an area worth exploring in the future. In addition, the impacts of syndecan-mediated calcium regulation and matrix turnover in inflammation is still not clear and requires further studies. Finally, syndecans may influence the expression of each other, which warrants further investigation to determine how the balancing of syndecans may help to regain tissue homeostasis during inflammation. Moreover, the temporal expression levels and the rate of shedding of syndecans during different stages of inflammation is unknown. Therefore, more studies need to be done in order to establish the potential use of syndecans as biomarkers of inflammation.

\section{AUTHOR CONTRIBUTIONS}

SG collected the data and compiled the review.

\section{FUNDING}

SG was supported by grants from the National Health and Medical Research Council, Australia (APP1161439) and Australian Research Council (DE190100174).

\section{ACKNOWLEDGMENTS}

The author thanks Prof. John Couchman, University of Copenhagen and Dr. Roger Pocock, Monash University for the comments on the manuscript.

2. Punchard NA, Whelan CJ, Adcock I. The journal of inflammation. J Inflamm. (2004) 1:1. doi: 10.1186/1476-9255-1-1

3. Ueha S, Shand FH, Matsushima K. Cellular and molecular mechanisms of chronic inflammation-associated organ fibrosis. 


\section{Front Immunol. (2012) 3:71. doi: 10.3389/fimmu.2012.}

00071 Costa C, Incio J, Soares R. Angiogenesis and chronic inflammation: cause or consequence? Angiogenesis. (2007) 10:149-66. doi: 10.1007/s10456-007-9074-0

5. Pober JS, Sessa WC. Inflammation and the blood microvascular system. Cold Spring Harb Perspect Biol. (2014) 7:a016345. doi: 10.1101/cshperspect.a016345

6. Ashley NT, Weil ZM, Nelson RJ. Inflammation: mechanisms, costs, and natural variation. Ann Rev Ecol Evol Syst. (2012) 43:385-406. doi: 10.1146/annurev-ecolsys-040212-092530

7. Roach JC, Glusman G, Rowen L, Kaur A, Purcell MK, Smith KD, et al. The evolution of vertebrate Toll-like receptors. Proc Natl Acad Sci USA. (2005) 102:9577-82. doi: 10.1073/pnas.0502272102

8. Ye Z, Ting JP. NLR, the nucleotide-binding domain leucinerich repeat containing gene family. Curr Opin Immunol. (2008) 20:3-9. doi: 10.1016/j.coi.2008.01.003

9. Liu T, Zhang L, Joo D, Sun SC. NF-кB signaling in inflammation. Signal Transduct Target Ther. (2017) 2:17023. doi: 10.1038/sigtrans.2017.23

10. Zhang JM, An J. Cytokines, inflammation, and pain. Int Anesthesiol Clin. (2007) 45:27-37. doi: 10.1097/AIA.0b013e318034194e

11. Lacy P. Mechanisms of degranulation in neutrophils. Allergy Asthma Clin Immunol. (2006) 2:98-108. doi: 10.1186/1710-1492-2-3-98

12. Nathan C. Points of control in inflammation. Nature. (2002) 420:84652. doi: 10.1038 /nature 01320

13. Xian X, Gopal S, Couchman JR. Syndecans as receptors and organizers of the extracellular matrix. Cell Tissue Res. (2010) 339:31-46. doi: 10.1007/s00441-009-0829-3

14. Gopal S, Bober A, Whiteford JR, Multhaupt HA, Yoneda A, Couchman JR. Heparan sulfate chain valency controls syndecan-4 function in cell adhesion. J Biol Chem. (2010) 285:14247-58. doi: 10.1074/jbc.M109.056945

15. Oh ES, Woods A, Couchman JR. Syndecan-4 proteoglycan regulates the distribution and activity of protein kinase C. J Biol Chem. (1997) 272:81336. doi: $10.1074 /$ jbc. 272.13 .8133

16. Oh ES, Woods A, Lim ST, Theibert AW, Couchman JR. Syndecan-4 proteoglycan cytoplasmic domain and phosphatidylinositol 4,5-bisphosphate coordinately regulate protein kinase C activity. J Biol Chem. (1998) 273:106249. doi: $10.1074 /$ jbc.273.17.10624

17. De Rossi G, Evans AR, Kay E, Woodfin A, McKay TR, Nourshargh S, et al. Shed syndecan-2 inhibits angiogenesis. J Cell Sci. (2014) 127:478899. doi: $10.1242 /$ jcs. 153015

18. De Rossi G, Whiteford JR. Syndecans in angiogenesis and endothelial cell biology. Biochem Soc Trans. (2014) 42:1643-6. doi: 10.1042/BST201 40232

19. Segaliny AI, Brion R, Mortier E, Maillasson M, Cherel M, Jacques Y, et al. Syndecan-1 regulates the biological activities of interleukin-34. Biochim Biophys Acta. (2015) 1853:1010-21. doi: 10.1016/j.bbamcr.2015.01.023

20. Hassan H, Greve B, Pavao MS, Kiesel L, Ibrahim SA, Götte M. Syndecan-1 modulates beta-integrin-dependent and interleukin-6-dependent functions in breast cancer cell adhesion, migration, and resistance to irradiation. FEBS J. (2013) 280:2216-27. doi: 10.1111/febs.12111

21. Götte M. Syndecans in inflammation. FASEB J. (2003) 17:57591. doi: 10.1096/fj.02-0739rev

22. Götte M, Joussen AM, Klein C, Andre P, Wagner DD, Hinkes MT, et al. Role of syndecan-1 in leukocyte-endothelial interactions in the ocular vasculature. Invest Ophthalmol Vis Sci. (2002) 43:1135-41.

23. Ishiguro K, Kadomatsu K, Kojima T, Muramatsu H, Iwase M, Yoshikai Y, et al. Syndecan-4 deficiency leads to high mortality of lipopolysaccharide-injected mice. J Biol Chem. (2001) 276:47483-8. doi: 10.1074/jbc.M106268200

24. Alexopoulou AN, Multhaupt HA, Couchman JR. Syndecans in wound healing, inflammation and vascular biology. Int J Biochem Cell Biol. (2007) 39:505-28. doi: 10.1016/j.biocel.2006.10.014

25. Halden Y, Rek A, Atzenhofer W, Szilak L, Wabnig A, Kungl AJ. Interleukin-8 binds to syndecan-2 on human endothelial cells. Biochem J. (2004) 377:5338. doi: 10.1042/bj20030729

26. Choi S, Chung H, Hong H, Kim SY, Kim SE, Seoh JY, et al. Inflammatory hypoxia induces syndecan-2 expression through IL-1betamediated FOXO3a activation in colonic epithelia. FASEB J. (2017) 31:151630. doi: 10.1096/fj.201601098R
27. Pei S, Zheng D, Wang Z, Hu X, Pan S, Wang H. Elevated soluble syndecan-1 levels in neuromyelitis optica are associated with disease severity. Cytokine. (2018) 111:140-5. doi: 10.1016/j.cyto.2018.08.017

28. Voyvodic PL, Min D, Liu R, Williams E, Chitalia V, Dunn AK, et al. Loss of syndecan-1 induces a pro-inflammatory phenotype in endothelial cells with a dysregulated response to atheroprotective flow. J Biol Chem. (2014) 289:9547-59. doi: 10.1074/jbc.M113.541573

29. Couchman JR. Transmembrane signaling proteoglycans. Annu Rev Cell Dev Biol. (2010) 26:89-114. doi: 10.1146/annurev-cellbio-100109-104126

30. Couchman JR, Pataki CA. An introduction to proteoglycans and their localization. J Histochem Cytochem. (2012) 60:88597. doi: 10.1369/0022155412464638

31. Giuffrè L, Cordey AS, Monai N, Tardy Y, Schapira M, Spertini O. Monocyte adhesion to activated aortic endothelium: role of L-selectin and heparan sulfate proteoglycans. J Cell Biol. (1997) 136:945-56. doi: 10.1083/jcb.136.4.945

32. Echtermeyer F, Streit M, Wilcox-Adelman S, Saoncella S, Denhez F, Detmar $\mathrm{M}$, et al. Delayed wound repair and impaired angiogenesis in mice lacking syndecan-4. J Clin Invest. (2001) 107:R9-r14. doi: 10.1172/JCI10559

33. Vanhoutte D, Schellings MW, Götte M, Swinnen M, Herias V, Wild MK, et al. Increased expression of syndecan-1 protects against cardiac dilatation and dysfunction after myocardial infarction. Circulation. (2007) 115:47582. doi: 10.1161/CIRCULATIONAHA.106.644609

34. Brauer R, Ge L, Schlesinger SY, Birkland TP, Huang Y, Parimon T, et al. Syndecan-1 attenuates lung injury during influenza infection by potentiating c-Met signaling to suppress epithelial apoptosis. Am J Respir Crit Care Med. (2016) 194:333-44. doi: 10.1164/rccm.201509-1878OC

35. Angsana J, Chen J, Smith S, Xiao J, Wen J, Liu L, et al. Syndecan-1 modulates the motility and resolution responses of macrophages. Arterioscler Thromb Vasc Biol. (2015) 35:332-40. doi: 10.1161/ATVBAHA.114.304720

36. Kharabi Masouleh B, Ten Dam GB, Wild MK, Seelige R, van der Vlag J, Rops AL, et al. Role of the heparan sulfate proteoglycan syndecan1 (CD138) in delayed-type hypersensitivity. J Immunol. (2009) 182:498593. doi: 10.4049/jimmunol.0800574

37. Floer M, Götte M, Wild MK, Heidemann J, Gassar ES, Domschke W, et al. Enoxaparin improves the course of dextran sodium sulfateinduced colitis in syndecan-1-deficient mice. Am J Pathol. (2010) 176:14657. doi: 10.2353/ajpath.2010.080639

38. Hyun YM, Lefort CT, Kim M. Leukocyte integrins and their ligand interactions. Immunol Res. (2009) 45:195208. doi: 10.1007/s12026-009-8101-1

39. Kaneider NC, Reinisch CM, Dunzendorfer S, Römisch J, Wiedermann CJ. Syndecan-4 mediates antithrombin-induced chemotaxis of human peripheral blood lymphocytes and monocytes. J Cell Sci. (2002) 115:22736. doi: $10.1186 / \mathrm{cc} 1575$

40. Polte T, Petzold S, Bertrand J, Schütze N, Hinz D, Simon JC, et al. Critical role for syndecan-4 in dendritic cell migration during development of allergic airway inflammation. Nat Commun. (2015) 6:7554. doi: 10.1038/ncomms8554

41. Eustace AD, McNaughton EF, King S, Kehoe O, Kungl A, Mattey D, et al. Soluble syndecan-3 binds chemokines, reduces leukocyte migration in vitro and ameliorates disease severity in models of rheumatoid arthritis. Arthritis Res Ther. (2019) 21:172. doi: 10.1186/s13075-019-1939-2

42. Kuschert GS, Coulin F, Power CA, Proudfoot AE, Hubbard RE, Hoogewerf AJ, et al. Glycosaminoglycans interact selectively with chemokines and modulate receptor binding and cellular responses. Biochemistry. (1999) 38:1295968. doi: 10.1021/bi990711d

43. Webb LM, Ehrengruber MU, Clark-Lewis I, Baggiolini M, Rot A. Binding to heparan sulfate or heparin enhances neutrophil responses to interleukin 8. Proc Natl Acad Sci USA. (1993) 90:7158-62. doi: 10.1073/pnas.90.15.7158

44. Li Q, Park PW, Wilson CL, Parks WC. Matrilysin shedding of syndecan-1 regulates chemokine mobilization and transepithelial efflux of neutrophils in acute lung injury. Cell. (2002) 111:63546. doi: 10.1016/S0092-8674(02)01079-6

45. Marshall LJ, Ramdin LS, Brooks T, DPhil PC, Shute JK. Plasminogen activator inhibitor-1 supports IL-8-mediated neutrophil transendothelial migration by inhibition of the constitutive shedding of endothelial IL8/heparan sulfate/syndecan-1 complexes. J Immunol. (2003) 171:205765. doi: 10.4049/jimmunol.171.4.2057 
46. Sarris M, Masson JB, Maurin D, Van der Aa LM, Boudinot P, Lortat-Jacob $\mathrm{H}$, et al. Inflammatory chemokines direct and restrict leukocyte migration within live tissues as glycan-bound gradients. Curr Biol. (2012) 22:237582. doi: 10.1016/j.cub.2012.11.018

47. Jaiswal AK, Sadasivam M, Archer NK, Miller RJ, Dillen CA, Ravipati A, et al. Syndecan-1 regulates psoriasiform dermatitis by controlling homeostasis of IL-17-Producing $\gamma \delta$ T Cells. J Immunol. (2018) 201:165161. doi: 10.4049/jimmunol.1800104

48. Gong GQ, Ren FF, Wang YJ, Wan L, Chen S, Yuan J, et al. Expression of IL-17 and syndecan-1 in nasal polyps and their correlation with nasal polyps. J Huazhong Univ Sci Technolog Med Sci. (2017) 37:4128. doi: 10.1007/s11596-017-1749-1

49. Hong H, Song HK, Hwang ES, Lee AR, Han DS, Kim SE, et al. Up-regulation of syndecan-2 in proximal colon correlates with acute inflammation. FASEB J. (2019) 33:11381-95. doi: 10.1096/fj.201900561R

50. Tanino Y, Chang MY, Wang X, Gill SE, Skerrett S, McGuire JK, et al. Syndecan4 regulates early neutrophil migration and pulmonary inflammation in response to lipopolysaccharide. Am J Respir Cell Mol Biol. (2012) 47:196202. doi: 10.1165/rcmb.2011-0294OC

51. Sebestyén A, Gallai M, Knittel T, Ambrust T, Ramadori G, Kovalszky I. Cytokine regulation of syndecan expression in cells of liver origin. Cytokine. (2000) 12:1557-60. doi: 10.1006/cyto.2000.0754

52. Worapamorn W, Tam SP, Li H, Haase HR, Bartold PM. Cytokine regulation of syndecan-1 and-2 gene expression in human periodontal fibroblasts and osteoblasts. J Periodontal Res. (2002) 37:273-8. doi: 10.1034/j.1600-0765.2002.01610.x

53. Vuong TT, Reine TM, Sudworth A, Jenssen TG, Kolset SO. Syndecan-4 is a major syndecan in primary human endothelial cells in vitro, modulated by inflammatory stimuli and involved in wound healing. J Histochem Cytochem. (2015) 63:280-92. doi: 10.1369/0022155415568995

54. Day RM, Mitchell TJ, Knight SC, Forbes A. Regulation of epithelial syndecan-1 expression by inflammatory cytokines. Cytokine. (2003) 21:22433. doi: 10.1016/S1043-4666(03)00091-7

55. Kehoe O, Kalia N, King S, Eustace A, Boyes C, Reizes O, et al. Syndecan-3 is selectively pro-inflammatory in the joint and contributes to antigen-induced arthritis in mice. Arthritis Res Ther. (2014) 16:R148. doi: 10.1186/ar4610

56. Bonnans C, Chou J, Werb Z. Remodelling the extracellular matrix in development and disease. Nat Rev Mol Cell Biol. (2014) 15:786801. doi: $10.1038 / \mathrm{nrm} 3904$

57. Siwik DA, Colucci WS. Regulation of matrix metalloproteinases by cytokines and reactive oxygen/nitrogen species in the myocardium. Heart Fail Rev. (2004) 9:43-51. doi: 10.1023/B:HREV.0000011393.40674.13

58. Manicone AM, McGuire JK. Matrix metalloproteinases as modulators of inflammation. Semin Cell Dev Biol. (2008) 19:34-41. doi: 10.1016/j.semcdb.2007.07.003

59. Cox TR, Erler JT. Remodeling and homeostasis of the extracellular matrix: implications for fibrotic diseases and cancer. Dis Model Mech. (2011) 4:16578. doi: 10.1242/dmm.004077

60. Lunde IG, Herum KM, Carlson CC, Christensen G. Syndecans in heart fibrosis. Cell Tissue Res. (2016) 365:539-52. doi: 10.1007/s00441-016-2454-2

61. Strand ME, Aronsen JM, Braathen B, Sjaastad I, Kvaløy H, Tønnessen T, et al. Shedding of syndecan- 4 promotes immune cell recruitment and mitigates cardiac dysfunction after lipopolysaccharide challenge in mice. J Mol Cell Cardiol. (2015) 88:133-44. doi: 10.1016/j.yjmcc.2015.10.003

62. Tanino Y, Wang X, Nikaido T, Misa K, Sato Y, Togawa R, et al. Syndecan4 inhibits the development of pulmonary fibrosis by attenuating TGF- $\beta$ signaling. Int J Mol Sci. (2019) 20:4989. doi: 10.3390/ijms20204989

63. Jiang D, Liang J, Campanella GS, Guo R, Yu S, Xie T, et al. Inhibition of pulmonary fibrosis in mice by CXCL10 requires glycosaminoglycan binding and syndecan-4. J Clin Invest. (2010) 120:2049-57. doi: 10.1172/JCI38644

64. Schaefer A, Hordijk PL. Cell-stiffness-induced mechanosignaling - a key driver of leukocyte transendothelial migration. J Cell Sci. (2015) 128:222130. doi: 10.1242/jcs. 163055

65. Okina E, Grossi A, Gopal S, Multhaupt HA, Couchman JR. Alpha-actinin interactions with syndecan-4 are integral to fibroblast-matrix adhesion and regulate cytoskeletal architecture. Int J Biochem Cell Biol. (2012) 44:216174. doi: 10.1016/j.biocel.2012.08.017
66. Gopal S, Multhaupt HAB, Pocock R, Couchman JR. Cell-extracellular matrix and cell-cell adhesion are linked by syndecan-4. Matrix Biol. (2017) 60-61:5769. doi: 10.1016/j.matbio.2016.10.006

67. Couchman JR, Gopal S, Lim HC, Nørgaard S, Multhaupt HA. Syndecans: from peripheral coreceptors to mainstream regulators of cell behaviour. Int J Exp Pathol. (2015) 96:1-10. doi: 10.1111/iep.12112

68. Gopal S, Søgaard P, Multhaupt HA, Pataki C, Okina E, Xian $\mathrm{X}$, et al. Transmembrane proteoglycans control stretch-activated channels to set cytosolic calcium levels. J Cell Biol. (2015) 210:1199-211. doi: 10.1083/jcb.201501060

69. Subramanian SV, Fitzgerald ML, Bernfield M. Regulated shedding of syndecan-1 and-4 ectodomains by thrombin and growth factor receptor activation. J Biol Chem. (1997) 272:14713-20. doi: 10.1074/jbc.272.23.14713

70. Manon-Jensen T, Multhaupt HA, Couchman JR. Mapping of matrix metalloproteinase cleavage sites on syndecan-1 and syndecan-4 ectodomains. FEBS J. (2013) 280:2320-31. doi: 10.1111/febs.12174

71. Kainulainen V, Wang H, Schick C, Bernfield M. Syndecans, heparan sulfate proteoglycans, maintain the proteolytic balance of acute wound fluids. J Biol Chem. (1998) 273:11563-9. doi: 10.1074/jbc.273.19.11563

72. Zhang Y, Wang Z, Liu J, Zhang Z, Chen Y. Suppressing syndecan1 shedding ameliorates intestinal epithelial inflammation through inhibiting NF- $\kappa \mathrm{B}$ Pathway and TNF- $\alpha$. Gastroenterol Res Pract. (2016) 2016:6421351. doi: 10.1155/2016/6421351

73. Gill SE, Nadler ST, Li Q, Frevert CW, Park PW, Chen P, et al. Shedding of syndecan-1/CXCL1 complexes by matrix metalloproteinase 7 functions as an epithelial checkpoint of neutrophil activation. Am J Respir Cell Mol Biol. (2016) 55:243-51. doi: 10.1165/rcmb.2015-0193OC

74. Xu J, Park PW, Kheradmand F, Corry DB. Endogenous attenuation of allergic lung inflammation by syndecan-1. J Immunol. (2005) 174:575865. doi: 10.4049/jimmunol.174.9.5758

75. Hayashida K, Parks WC, Park PW. Syndecan-1 shedding facilitates the resolution of neutrophilic inflammation by removing sequestered CXC chemokines. Blood. (2009) 114:3033-43. doi: 10.1182/blood-2009-02-204966

76. Zhang C, Guo F, Chang M, Zhou Z, Yi L, Gao C, et al. Exosome-delivered syndecan-1 rescues acute lung injury via a FAK/p190RhoGAP/RhoA/ROCK/NF-кB signaling axis and glycocalyx enhancement. Exp Cell Res. (2019) 384:111596. doi: 10.1016/j.yexcr.2019.111596

77. Gonzalez Rodriguez E, Cardenas JC, Cox CS, Kitagawa RS, Stensballe J, Holcomb JB, et al. Traumatic brain injury is associated with increased syndecan-1 shedding in severely injured patients. Scand J Trauma Resusc Emerg Med. (2018) 26:102. doi: 10.1186/s13049-018-0565-3

78. Yablecovitch D, Oren A, Ben-Horin S, Fudim E, Eliakim R, Saker T, et al. Soluble syndecan-1: a novel biomarker of small bowel mucosal damage in children with celiac disease. Dig Dis Sci. (2017) 62:75560. doi: $10.1007 / \mathrm{s} 10620-016-4415-8$

79. Patterson AM. Soluble syndecan-1: does this biomarker address a seemingly insoluble problem in inflammatory bowel disease? Dig Dis Sci. (2015) 60:2222-4. doi: 10.1007/s10620-015-3669-x

80. Ibrahim SA, Gadalla R, El-Ghonaimy EA, Samir O, Mohamed HT, Hassan $\mathrm{H}$, et al. Syndecan-1 is a novel molecular marker for triple negative inflammatory breast cancer and modulates the cancer stem cell phenotype via the IL-6/STAT3, Notch and EGFR signaling pathways. Mol Cancer. (2017) 16:57. doi: 10.1186/s12943-017-0621-z

81. Walsh DA, Pearson CI. Angiogenesis in the pathogenesis of inflammatory joint and lung diseases. Arthritis Res. (2001) 3:147-53. doi: 10.1186/ar292

82. Szade A, Grochot-Przeczek A, Florczyk U, Jozkowicz A, Dulak J. Cellular and molecular mechanisms of inflammation-induced angiogenesis. IUBMB Life. (2015) 67:145-59. doi: 10.1002/iub.1358

83. Götte M, Bernfield M, Joussen AM. Increased leukocyteendothelial interactions in syndecan-1-deficient mice involve heparan sulfate-dependent and -independent steps. Curr Eye Res. (2005) 30:417-22. doi: 10.1080/02713680590956289

84. Elenius V, Götte M, Reizes O, Elenius K, Bernfield M. Inhibition by the soluble syndecan-1 ectodomains delays wound repair in mice overexpressing syndecan-1. J Biol Chem. (2004) 279:41928-35. doi: 10.1074/jbc.M404 506200 
85. Chen E, Hermanson S, Ekker SC. Syndecan-2 is essential for angiogenic sprouting during zebrafish development. Blood. (2004) 103:1710-9. doi: 10.1182/blood-2003-06-1783

86. Li R, Xie J, Wu H, Li G, Chen J, Chen Q, et al. Syndecan-4 shedding impairs macrovascular angiogenesis in diabetes mellitus. Biochem Biophys Res Commun. (2016) 474:15-21. doi: 10.1016/j.bbrc.2016.03.112

87. Aquino RS, Park PW. Glycosaminoglycans and infection. Front Biosci. (2016) 21:1260-77. doi: $10.2741 / 4455$

88. Rajas O, Quirós LM, Ortega M, Vazquez-Espinosa E, Merayo-Lloves J, Vazquez F, et al. Glycosaminoglycans are involved in bacterial adherence to lung cells. BMC Infect Dis. (2017) 17:319. doi: 10.1186/s12879-017-2418-5
Conflict of Interest: The author declares that the research was conducted in the absence of any commercial or financial relationships that could be construed as a potential conflict of interest.

Copyright (c) 2020 Gopal. This is an open-access article distributed under the terms of the Creative Commons Attribution License (CC BY). The use, distribution or reproduction in other forums is permitted, provided the original author(s) and the copyright owner(s) are credited and that the original publication in this journal is cited, in accordance with accepted academic practice. No use, distribution or reproduction is permitted which does not comply with these terms. 